\title{
A new molecular marker for species-specific identification of Microsporum canis
}

\author{
Anita Ciesielska ${ }^{1}$ (D) Paweł Stączek ${ }^{1}$ (D) \\ Received: 20 April 2020 / Accepted: 15 July 2020 / Published online: 21 July 2020 \\ (C) The Author(s) 2020
}

\begin{abstract}
Species identification of dermatophytes by conventional mycological methods based on macro- and microscopy analysis is time-consuming and has a lot of limitations such as slow fungal growth or low specificity. Thus, there is a need for the development of molecular methods that would provide reliable and prompt identification of this group of medically important fungi. The are many reports in the literature concerning PCR identification of dermatophyte species, but still, there are not many PCR assays for the separate detection of members of the genera Microsporum, especially Microsporum canis (zoophilic species) and Microsporum audouinii (anthropophilic species). The correct distinction of these species is important to determine the source of infection to implement the appropriate action to eliminate the path of infection transmission. In this paper, we present such a PCR-based method targeting velB gene that uses a set of two primers-Mc-VelB-F (5'-CTTCCCCACCCGCAACATC-3') and Mc-VelB-R (5'-TGTGGCTGCACCTGAGAGTGG$\left.3^{\prime}\right)$. The amplified fragment is specific due to the presence of (CAGCAC) $)_{8}$ microsatellite sequence only in the velB gene of M. canis. DNA from 153 fungal samples was used in PCR assay followed by electrophoretic analysis. The specificity of the designed set of primers was also confirmed using the online BLAST-Primer tool. The positive results were observed only in the case of $M$. canis isolates, and no positive results were obtained neither for other dermatophytes and non-dermatophyte fungi nor for other Eukaryotes, including the human genome sequence, as well as the representatives of bacterial and viral taxa. The developed PCR assay using the proposed Mc-VelB-F and Mc-velB-R primers can be included in the algorithm of $M$. canis detection in animals and humans.
\end{abstract}

Keywords Microsporum canis $\cdot$ PCR $\cdot$ Molecular identification $\cdot$ Molecular marker

\section{Introduction}

Tinea corporis and tinea capitis are the most common types of dermatophyte infections caused by Microsporum canis, less often by M. audouinii [1]. This kind of dermatophytosis occurs in all geographical areas, causing local endemics and even outbreaks, e.g., in kindergartens and schools. Traditional mycological identification mainly relied on a macroscopic and microscopic examination requiring experienced personnel [2]. Misidentification using conventional assays

Responsible Editor: Rosana Puccia.

Anita Ciesielska

anita.ciesielska@biol.uni.lodz.pl

1 Department of Microbial Genetics, Faculty of Biology and Environmental Protection, University of Łódź, Łódź, Poland was the main reason for the development of molecular methods based mainly on the PCR technique, which became fast and reliable alternatives. Correct identification of M. canis as an etiological agent of infection and effective elimination of the source of the fungus are the factors necessary to prevent further transmission. There are only a few $M$. canis molecular identification assays described in the literature, in which the ITS1 sequence of the ribosomal DNA or $\beta$-tubulin gene was used as molecular markers [3-5]. Here, we present a new, alternative set of PCR primers-Mc-VelB-F and Mc-VelB$\mathrm{R}$ - that are specific for the velB gene. The VelB (velvet-like B) protein is a light-dependent regulator that belongs to the velvet family proteins, which plays a key role in coordinating secondary metabolism and fungal development [6]. The purpose of this study was to validate the use of $v e l B$ gene as a new molecular marker for species identification of $M$. canis isolated from humans and animals as well as differentiation of M. canis from M. audouinii. 


\section{Material and methods}

We used 153 DNA samples isolated from fungi belonging to genera Trichophyton, Microsporum, Epidermophyton, Chrysosporium, and Candida which were obtained from Westerdijk Fungal Biodiversity Institute collection (formerly CBS-KNAW, Centraalbureau voor Schimmelcultures, Utrecht, Netherlands) or originated from the collection maintained in the Department of Microbial Genetics (DMG), Faculty of Biology and Environmental Protection, University of Łódź, Poland (Table 1). Traditional mycological identification was confirmed by PCR-RFLP targeting the ITS1-5.8S-ITS2 region [7] and sequencing of PCR products. Based on the alignment (Geneious software) of fungal velB gene sequence deposited in the NCBI nucleotide database (Accession no. XM_002845600), primers specific for M. canis-Mc-VelB-F (5'-CTTCCCCACCCGCAACATC$3^{\prime}$ ) and Mc-VelB-R (5'-TGTGGCTGCACCTGAGAGTGG3') - were designed using Primer 3 software [8]. Each PCR mixture $(20 \mu \mathrm{l})$ contained $1 \mu \mathrm{l}$ of genomic DNA (20 ng), $0.5 \mu \mathrm{l}$ of $0.5 \mu \mathrm{M}$ of each primer, $4 \mu \mathrm{l} 5 \mathrm{xGC}$ buffer, $0.4 \mu \mathrm{l}$ $10 \mathrm{mM}$ dNTPs, $1 \mu \mathrm{LMSO}, 12.4 \mu \mathrm{l}$ distilled water, and $0.2 \mu \mathrm{l}$ Phusion Hot Start II DNA Polymerase (Thermo Scientific). Reaction mixtures were preheated to $98^{\circ} \mathrm{C}$ for $5 \mathrm{~min}$, and then 35 PCR cycles were performed under the following conditions: $98{ }^{\circ} \mathrm{C}$ for $1 \mathrm{~min}, 68{ }^{\circ} \mathrm{C}$ for $1 \mathrm{~min}$, and $72{ }^{\circ} \mathrm{C}$ for $1 \mathrm{~min}$. Thermal cycles were finalized by polymerization at $72{ }^{\circ} \mathrm{C}$ for $5 \mathrm{~min}$. The PCR products were purified with PCR Purification Kit (Qiagen), and detection was performed by electrophoresis in $12 \%$ polyacrylamide gel stained with ethidium bromide and visualized by UV light. The primer pair was tested for specificity using the online Primer-BLAST tool (https://www.ncbi.nlm.nih.gov/tools/primer-blast/). The primers were blasted against several nucleotide collection BLAST databases, including fungi (taxid: 4751), eukaryota (taxid: 2759), bacteria (taxid: 2), viruses (taxid: 10239), and human DNA (taxid: 9606). Default settings were used, except for the primer specificity stringency that was set to ignore targets that have six or more mismatches to the primer. Additionally, a BLAST (Basic Local Alignment Search Tool) search using available NCBI database sequences of the velB gene of $M$. canis and other dermatophytes as well as fungi belonging to Ascomycota was conducted to identify microsatellite motif (CAGCAC) $)_{8}$

\section{Results and discussion}

In silico PCR validation using an online Primer-BLAST search showed that the designed Mc-VelB-F and Mc-VelB$\mathrm{R}$ primer set was binding exclusively to the target sequence (XM 002845600) of Microsporum canis CBS 113480 species. The results of this analysis revealed that the reported primer pair was very specific. The in vitro validation of these primers has shown that the PCR product of about $200 \mathrm{bp}$ was detected only in the case of $M$. canis DNA samples (Table 1, Fig. 1b). It is worth to emphasize that the amplified fragment of $M$. canis velB gene is very unique because of the presence of the microsatellite motif (CAGCAC) 8 (Fig. 1a). For that reason, we analyzed the available sequences of the $v e l B$ gene in other dermatophytes as well as other fungi belonging to Ascomycota deposited in the NCBI database such as Nannizzia gypsea (XM_003175030), Trichophyton rubrum (XM_003232653), Aspergillus niger (XM_001389016), Aspergillus flavus (GU815258), Aspergillus nidulans (EF540815), Aspergillus terreus (KY425759), Penicillium marneffei (XM_002148380), Ajellomyces dermatitidis (XM_002625878), Metarhizium brunneum (XM_014688378), Metarhizium acridum (XM_007812729), Verticillium dahliae (XM_009651032), Verticillium alfalfae (XM_003004840), Curvularia lunata (KY435512), Marssonina brunnea (XM_007292607), Beauveria bassiana (JX156415), Coccidioides immitis (XM_001238939), Colletotrichum orchidophilum (XM_022618517), Colletotrichum higginsianum (XM_018295991), Colletotrichum graminicola (XM_008095148), Pochonia chlamydosporia (XM_018291621), Gaeumannomyces tritici (XM_009219313), Magnaporthe oryzae (XM_003714558), Rasamsonia emersonii (XM_013468828), Talaromyces stipitatus (XM_002482648), and Beauveria bassiana (XM_008604835). According to the bioinformatic analysis, we have noticed that the specific microsatellite motif $(\mathrm{CAGCAC})_{8}$ located within the $v e l B$ gene is present only in the case of $M$. canis. Computer analysis indicated also that the shorter $(\mathrm{CAGCAC})_{5}$ motif was present in the case of $N$. gypsea velB gene. The CAGCAC sequence was present as a separate single motif in three locations within $v e l B$ gene of $C$. higginsianum, twice in the case of $C$. orchidophilum and $B$. bassiana, and once in the case of $V$. dahliae, $V$. alfalfae, M. acridum, C. lunata, A. nidulans, $M$. brunnea, B. bassiana (JX156415), P. chlamydosporia, M. oryzae, and T. stipitatus. In the remaining analyzed species, no CAGCAC motif was found.

In conclusion, in this report, we propose to use the nucleotide sequence of the velvet-like B gene (velB) as a new molecular marker containing a unique microsatellite motif (CAGCAC) $)_{8}$ for identification of $M$. canis. The designed, new species-specific primers are capable of distinguishing the target taxon-M. canis - from the other dermatophytes, and what is particularly important, the signal does not crossmatch with other closely related species of keratinolytic fungi as well as eukaryota, bacteria, viruses, and human DNA confirmed by Primer-BLAST analysis. Moreover, this procedure will be particularly useful in distinguishing zoophilic $M$. canis from anthropophilic $M$. audouinii, which are phylogenetically closely related species and can cause similar clinical 
Table 1 DNA samples used in the study and PCR results

\begin{tabular}{|c|c|c|c|}
\hline Fungi species & Collection & $\begin{array}{l}\text { No. of DNA } \\
\text { samples }\end{array}$ & $\begin{array}{l}\text { velB-specific PCR product } \\
(\sim 200 \mathrm{bp})\end{array}$ \\
\hline Microsporum canis $(\mathrm{A}, \mathrm{Z})$ & $\begin{array}{l}\text { CBS } 113480, \\
\text { DMG }\end{array}$ & $14(\mathrm{~A}) 29(\mathrm{Z})$ & Positive \\
\hline M. audouinii (A) & CBS 102894 & 1 & Negative \\
\hline Nannizzia gypsea $(\mathrm{G})$ & CBS 130813 & 1 & Negative \\
\hline Trichophyton rubrum (A) & $\begin{array}{l}\text { CBS } 120358, \\
\text { DMG }\end{array}$ & 21 & Negative \\
\hline T. interdigitale (A) & $\begin{array}{l}\text { CBS } 120357, \\
\text { DMG }\end{array}$ & 17 & Negative \\
\hline T. tonsurans (A) & $\begin{array}{l}\text { CBS } 109034, \\
\text { DMG }\end{array}$ & 3 & Negative \\
\hline T. verrucosum $(\mathrm{Z})$ & $\begin{array}{l}\text { CBS 102011, } \\
\text { DMG }\end{array}$ & 4 & Negative \\
\hline T. ajelloi $(\mathrm{G})$ & $\begin{array}{l}\text { CBS } 119779, \\
\text { DMG }\end{array}$ & 17 & Negative \\
\hline $\begin{array}{l}\text { Epidermophyton floccosum } \\
\text { (A) }\end{array}$ & $\begin{array}{l}\text { CBS } 100148, \\
\text { DMG }\end{array}$ & 4 & Negative \\
\hline $\begin{array}{l}\text { Chrysosporium } \\
\quad \text { keratinophilum }(\mathrm{Z})\end{array}$ & $\begin{array}{l}\text { CBS } 104.62 \\
\text { DMG }\end{array}$ & 21 & Negative \\
\hline Ch. tropicum $(\mathrm{Z})$ & $\begin{array}{l}\text { CBS } 171.62, \\
\text { DMG }\end{array}$ & 19 & Negative \\
\hline Candida albicans & DMG & 2 & Negative \\
\hline
\end{tabular}

A, anthropophilic; Z, zoophilic; G, geophilic; CBS, Centraalbureau voor Schimmelcultures (Westerdijk Fungal Biodiversity Institute); DMG, Department of Microbial Genetics

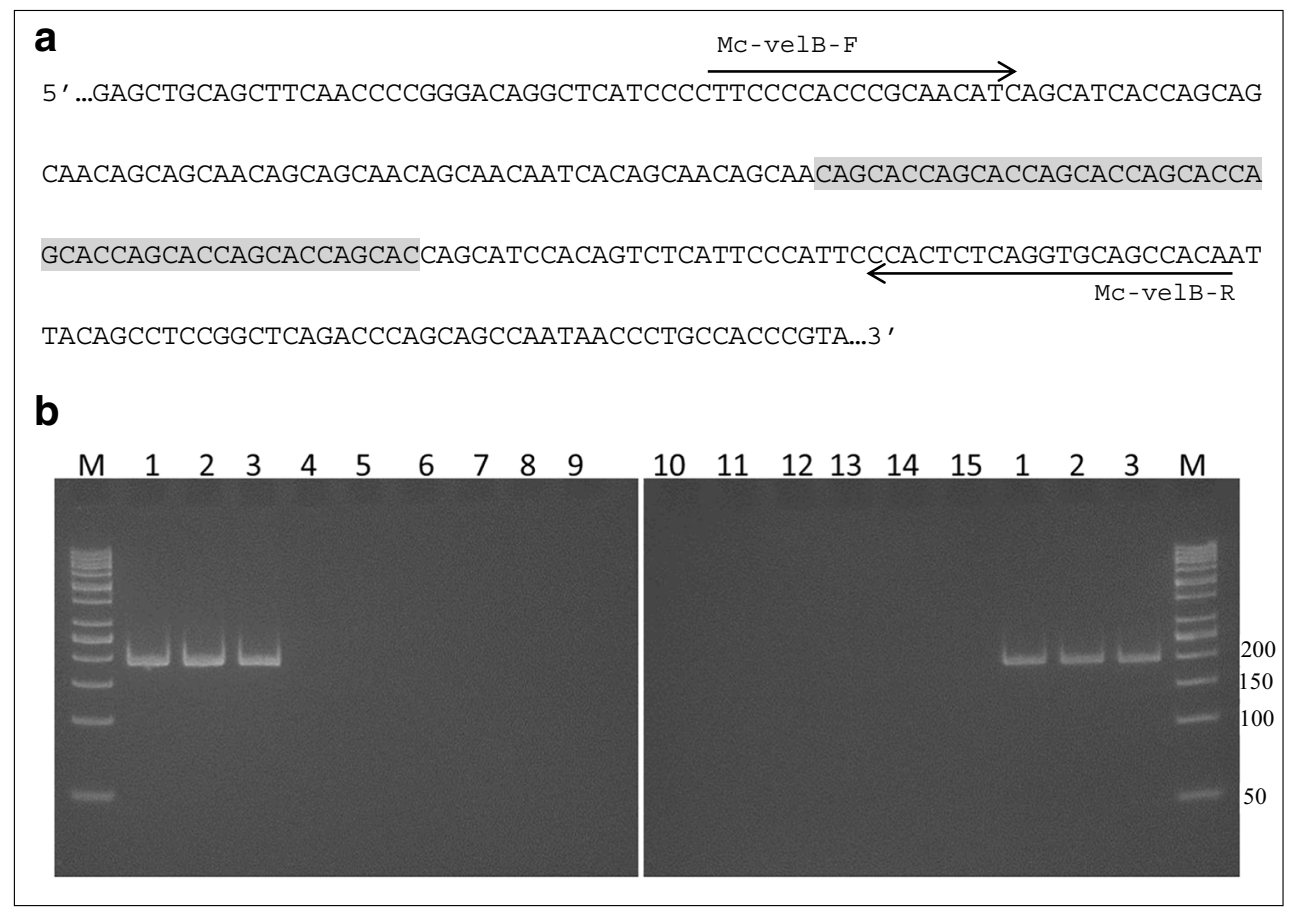

Fig. 1 a Representation of a fragment of the target sequence of velB gene (Accession no. XM_002845600) and direction of primers. Shaded area represents the unique microsatellite motif $(\mathrm{CAGCAC})_{8}$. b Exemplary specificity assay with the primers Mc-velB-F and Mc-velB-R. M, $50 \mathrm{bp}$ DNA Ladder (Thermo Scientific). Lanes 1-15 PCR reactions using $20 \mathrm{ng}$ of template DNA: 1, Microsporum canis CBS 113480; 2, M. canis DMG1; 3, M. canis DMG2; 4, Nannizzia gypsea CBS 130813; 5, M. audouinii CBS 102894; 6, Trichophyton rubrum CBS 120358; 7 ,
T. interdigitale CBS 120357; 8, T. tonsurans CBS 109034; 9, T. verrucosum CBS 102011; 10, T. ajjeloi CBS 119779; 11, Epidermophyton floccosum CBS 100148; 12, Chrysosporium keratinophilum CBS 104.62; 13, Ch. tropicum CBS 171.62; 14, C. albicans DMG; 15, NTC, no template control. CBS, Westerdijk Fungal Biodiversity Institute culture collection; DMG, Department of Microbial Genetics collection 
manifestations. We hope that the proposed identification assay can be a useful alternative or a supplement to the previously described algorithm of $M$. canis detection [3, 4].

Funding information This work was supported by grant 2014/13/B/NZ7/ 02307 from the National Science Centre, Poland.

\section{Compliance with ethical standards}

Conflict of interest The authors declare that they have no conflict of interest.

Open Access This article is licensed under a Creative Commons Attribution 4.0 International License, which permits use, sharing, adaptation, distribution and reproduction in any medium or format, as long as you give appropriate credit to the original author(s) and the source, provide a link to the Creative Commons licence, and indicate if changes were made. The images or other third party material in this article are included in the article's Creative Commons licence, unless indicated otherwise in a credit line to the material. If material is not included in the article's Creative Commons licence and your intended use is not permitted by statutory regulation or exceeds the permitted use, you will need to obtain permission directly from the copyright holder. To view a copy of this licence, visit http://creativecommons.org/licenses/by/4.0/.

\section{References}

1. Rezaei-Matehkolaei A, Makimura K, Sybren de Hoog G, Shidfar MR, Satoh K, Najafzadeh MJ, Mirhendi H (2012) Multilocus differentiation of the related dermatophytes Microsporum canis,
Microsporum ferrugineum and Microsporum audouinii. J Med Microbiol 61:57-63. https://doi.org/10.1099/jmm.0.036541-0

2. Dobrowolska A, Stączek P, Kaszuba A, Kozłowska M (2006) PCRRFLP analysis of the dermatophytes isolated from patients in Central Poland. J Dermatol Sci 42:71-74. https://doi.org/10.1016/j.jdermsci. 2006.01.001

3. Brillowska-Dąbrowska A, MichaŁek E, Saunte DML, Sogaard Nielsen S, Arendrup MC (2013) PCR test for Microsporum canis identification. Med Mycol 51:576-579. https://doi.org/10.3109/ 13693786.2012.755741

4. Brillowska-Dąbrowska A, Wierkowska A, Lindhardt Saunte DM, Arendrup MC (2010) Diagnostic PCR tests for Microsporum audouinii, M. canis and Trichophyton infections. Med Mycol 48: 486-490. https://doi.org/10.3109/13693780903312454

5. Kobylak N, Bykowska B, Kurzyk E, Nowicki R, BrillowskaDąbrowska A (2016) PCR and real-time PCR approaches to the identification of Arthroderma otae species Microsporum canis and Microsporum audouinii/Microsporum ferrugineum. J Eur Acad Dermatol Venereol 30:1819-1822. https://doi.org/10.1111/jdv. 13681

6. Bayram Ö, Braus GH (2012) Coordination of secondary metabolism and development in fungi: the velvet family of regulatory proteins. FEMS Microbiol Rev 36:1-24. https://doi.org/10.1111/j.1574-6976. 2011.00285.x

7. Jackson CJ, Barton RC, Evans EGV (1999) Species identification and strain differentiation of dermatophyte fungi by analysis of ribosomal-DNA intergenic spacer regions. J Clin Microbiol 37: 931-936

8. Koressaar T, Remm M (2007) Enhancements and modifications of primer design program Primer3. Bioinformatics 23:1289-1291

Publisher's note Springer Nature remains neutral with regard to jurisdictional claims in published maps and institutional affiliations. 